\title{
Darío Casapiccola. La Iglesia partida. Rosario: La crisis de 1969. Rosario: Logos, 2016, 270 páginas
}

\author{
María Alejandra Bertolotto ${ }^{1}$
}

$\mathrm{E}^{\mathrm{n}}$ 1969 se produjo en Rosario (Argentina) un conflicto en el seno de la Iglesia cuando un grupo de sacerdotes se enfrentó al arzobispo Guillermo Bolatti, por que sostenían que el clérigo no estaba administrando la arquidiócesis de acuerdo a las innovaciones surgidas del Concilio Vaticano II iniciado en 1962. Los sacerdotes rebeldes cuestionaron duramente a Bolatti y le presentaron sus renuncias. Ambos extremos del conflicto recurrieron a la autoridad del papa con el objetivo de imponer sus posturas. Darío Casapiccola reconstruye este suceso de manera detallada, analizando un profuso corpus de fuentes primarias escritas y orales. La Iglesia partida tiene en cuenta tanto las características y dinámicas propias del conflicto, como también sus relaciones con procesos más amplios, cuestión que enriquece el trabajo. La obra analiza las ideas, expectativas, estrategias y formas de acción de los actores involucrados ante el "estímulo" que constituyó el conflicto. En concreto, a través de un problema local y argentino se abordan los problemas suscitados en la organización jerárquica de la Iglesia en el marco del Concilio Vaticano II y la Conferencia de Medellín.

El estudio de Casapiccola se puede considerar un aporte al análisis del proceso de secularización, que ha sido revisado en su sentido más tradicional. En efecto, se enfatiza el factor multidimensional de la secularización, en tanto proceso complejo que puede adquirir rasgos disímiles en Europa y América. Se ha destacado que el factor religioso no desaparece ni tampoco queda excluido de la vida pública, como tradicionalmente se afirmaba. La secularización es entendida como un proceso de recomposición de lo religioso donde los comportamientos y las creencias ganan autonomía en los sujetos. A tono con estas miradas, La Iglesia partida constituye un trabajo valioso debido a que, al reconstruir un hecho específico a través de un exhaustivo trabajo de investigación y análisis de fuentes escritas y orales, su autor contribuye a analizar el mencionado proceso de secularización desde una perspectiva histórica.

La teoría de la secularización se pregunta acerca del lugar que tiene la

\footnotetext{
1 Universidad de Buenos Aires/Universidad de San Andrés. Argentina. Correo electrónico: profalejandrabertolotto@ gmail.com
} 
religión en el mundo moderno. Tradicionalmente, se identificó a la Iglesia católica como una institución dogmática, y por lo tanto contraria a la modernización. Sin embargo, hoy los alcances de estas ideas son cuestionados. La Iglesia y el catolicismo dialogaron con el proceso de modernización. En efecto, durante el Concilio Vaticano II se propuso la profundización e institucionalización de un aggiornamento que venía perfilándose décadas antes. En este sentido, el catolicismo argentino tenía elementos modernos previamente al Concilio: los congresos eucarísticos, la identificación con la nación, los círculos obreros, prensa católica, las movilizaciones callejeras.

El trabajo de Casapiccola muestra las tensiones producidas en la Iglesia en su relación con el proceso de modernización, dentro del contexto del Concilio Vaticano II y la Conferencia de Medellín. ¿Hasta dónde iban a llegar los cambios? ¿Cómo se interpretarían sus conclusiones? ¿Dónde se iba a poner el límite de dichos cambios? Durante el conflicto sucedido en Rosario entre Bolatti y los sacerdotes, los actores buscaron interpelar a la opinión pública, utilizando los medios de comunicación. El trabajo evidencia, entonces, estas tensiones que marcan a una institución con fuertes componentes "tradicionales" y "dogmáticos" que sin embargo se vale de elementos propiamente modernos, como la prensa.

En el primer capítulo, el autor analiza el Concilio Vaticano II y la Conferencia de Medellín en los aspectos vinculados con el conflicto rosarino. Según Casapiccola, dicho episodio fue producto directo del contexto eclesial de desarrollo e implementación del Concilio Vaticano II convocado por Juan XXIII y conducido luego de su muerte por el papa Pablo VI. A partir de este momento existió la conciencia de que se había producido un "cambio", el problema era entonces, cuál iba a ser la profundidad de ese cambio y qué supondría en relación a la estructura de poder en la Iglesia. A grandes rasgos, fueron delimitándose dos grandes posturas: aquellos sacerdotes y laicos defensores y militantes del cambio ("renovadores", "progresistas" y "postconciliares"), y aquellos que llamaban la atención acerca de la necesidad de estudiar cada modificación con el objetivo de no subvertir el dogma ("conservador", "preconciliar", "tradicionalista" y "reaccionario"). Una cuestión clave era la figura del obispo y su autoridad: lo que estuvo en juego en Rosario fue la obediencia misma y su concepción, e incluso la unidad de la Iglesia.

El segundo capítulo se centra en las tensiones generadas a partir del Concilio Vaticano II. Aquí el autor sostiene que la crisis rosarina puede concebirse como uno más de los focos de conflicto postconciliares y que si bien la jerarquía promovió los cambios, éstos adquirieron una dinámica propia. El autor analiza las características del episcopado argentino al momento de la crisis 
rosarina teniendo en cuenta su composición etaria, sus orígenes y su fuerte alineamiento con Roma. Esta última cuestión, determinará el rol central del papa en las disputas al interior de la Iglesia argentina. Casapiccola elabora a partir de casos sucedidos en Argentina, América y Europa, un "modelo" de conflicto posconciliar caracterizado por el surgimiento de un grupo de sacerdotes diocesanos contestatarios que se enfrentaban a un obispo particularmente conservador: el grupo realizaba un escrito para la autoridad eclesiástica y también para el Vaticano. Los sacerdotes solían denunciar la falta de adecuación a los preceptos del Concilio y de Medellín, la inexistencia de diálogo con el obispo, señalaban la ausencia de compromiso con el cambio social, o llamaban la atención acerca de posturas autoritarias. Es decir, aquí el texto plantea la necesidad de comprender los sucesos de Rosario en un contexto mayor signado por los ecos del Concilio Vaticano II y las disputas que generó su implementación.

El tercer capítulo estudia la arquidiócesis de Rosario y los principales actores del conflicto. La diócesis de Rosario fue creada en 1934 y Guillermo Bolatti la presidió desde 1961. En el año 1963 fue elevada a la categoría de arquidiócesis. Rosario era uno de los arzobispados más importantes de los doce que había en Argentina y Bolatti había sido fundamental en este proceso de crecimiento. Otro actor clave del conflicto fue el papa. Casapiccola destaca que Pablo VI procuró destacar la obediencia a la autoridad en la Iglesia, y cómo ésta se había reafirmado y perfeccionado en el Concilio Vaticano II. Ahora bien, el papa también advertía que las enseñanzas conciliares no constituían toda la doctrina católica, que era mucho más amplia. Por otro lado, el autor Ilama la atención acerca de la formación de un "grupo disidente" de sacerdotes que se alejó de la postura de Bolatti. El grupo estaba formado por sacerdotes jóvenes y se nucleaba alrededor de Armando Amirati. También, dentro del grupo se encontraban otros sacerdotes que habían colaborado con la Juventud Obrera Católica, rama obrera y juvenil de la Acción Católica Argentina. Para 1958 el grupo estaba formado, muchos de sus sacerdotes adherían al Movimiento de Sacerdotes para el Tercer Mundo y pensaban que Bolatti en realidad no estaba de acuerdo con los cambios planteados en el Concilio Vaticano II. Al mismo tiempo, el autor resalta la llegada a Rosario de siete sacerdotes españoles que comenzaron a trabajar en las zonas periféricas y se identificaron con Amirati. En suma, el "grupo disidente" se caracterizaba por defender la "Iglesia de los pobres". Unas semanas después de que terminara la Conferencia de Medellín, el grupo le entregó al obispo -y luego a la Conferencia Episcopal Argentina (CEA) - una carta donde exponía la necesidad de actuar de acuerdo a dicha Conferencia y manifestaba su preocupación por la falta de diálogo.

El cuarto capítulo constituye un pormenorizado análisis de la crisis 
rosarina de 1969. Como el obispo y la CEA se negaron a hacer lugar a los reclamos, los sacerdotes elevaron un escrito al Vaticano. Esta vez, la carta estuvo firmada por casi la tercera parte del clero secular de la arquidiócesis. Ambas partes estaban apoyadas por grupos de laicos y sacerdotes. El problema se trasladó rápidamente al ámbito de los medios de comunicación nacionales, cuestión que Casapiccola analiza detalladamente, haciendo énfasis en la importancia de la opinión pública en el devenir de la crisis. Los actores intentaron influir en ésta dado que consideraron que era una instancia importante de definición del conflicto. La crisis siguió in crescendo hasta que treinta sacerdotes presentaron su renuncia. Ante esto, Bolatti viajó a Roma. Ambos bandos buscaban en la autoridad vaticana, su legitimación y la definición del conflicto.

En el capítulo cinco, el autor se concentra en la siguiente etapa de la crisis, caracterizada por la actividad de Bolatti en Roma y la escalada nacional del conflicto. Este último punto, se evidencia en un documento dado a conocer por un importante número de sacerdotes que se solidarizaba con el grupo de renunciantes. El texto fue reproducido en la revista Cristianismo y Revolución y en el diario La Nación. Casapiccola destaca el elevado número de adhesiones (unas 350 firmas), evidencia la importancia que había adquirido la crisis rosarina en el plano nacional. Aun así, sostiene el autor, el desenlace del conflicto podía entreverse en los dichos del papa más allá de que ambas partes creyeran constituir la verdadera Iglesia.

El último capítulo examina el final de la crisis, signado por el regreso de Bolatti a Rosario con una carta de Pablo VI que reafirmaba su autoridad. El arzobispo leyó la carta en una misa en la Catedral de Rosario ante sacerdotes y feligreses. El texto apelaba a la unión y a la dócil colaboración con la autoridad de la arquidiócesis. Bolatti intentó una conciliación con los sacerdotes, llamó al diálogo y se negó a aceptar que los renunciantes se alejaran de la arquidiócesis. Sin embargo, el grupo se mantuvo firme. Finalmente, se produjeron veintiocho renuncias en Rosario. El conflicto tuvo una última escalada, dado que algunos feligreses se negaron a aceptar a los nuevos sacerdotes y ocuparon las parroquias y vicarías que habían estado a cargo de éstos. Parte del laicado se manejó, entonces, con total autonomía con respecto a la autoridad. En Cañada de Gómez, la parroquia de Amirati, la situación se tornó violenta cuando la policía tuvo que desalojar a los feligreses que no permitían ingresar al nuevo sacerdote. Luego de esto, el grupo de sacerdotes disidentes se disgregó. Muchos de sus integrantes fueron detenidos a lo largo de la década. En los años '70, casi la mitad abandonó el sacerdocio.

En resumen, La Iglesia partida constituye un aporte que echa luz sobre los conflictos generados en el período posconciliar teniendo en cuenta su 
complejidad. El trabajo advierte que estas disputas excedieron las cuestiones religiosas; la crisis rosarina tuvo una clara relación con la radicalización de la política de la década de 1960. A partir del análisis de un caso, Casapiccola responde una de las preguntas fundamentales que surgió del Concilio Vaticano II: ¿cuáles eran los límites del cambio? Como vimos, en un plano mayor, la obra realiza una contribución desde una perspectiva histórica al examen de los procesos de modernización y secularización. 